\title{
SiM
}

\section{Teaching Across Disciplines and Institutions}

\author{
By Karen R. Hickman and Melanie Murphy
}

everal members of the Range Science Education Council (RSEC) are in rangeland programs that are being challenged by their administration to broaden the scope of courses to attract a wider audience, thus increasing enrollment, and to alter how the courses are taught (e.g., traditional face-to-face on campus, online, distance education). The challenges we face have been brought about by a couple of major issues. First, too few students are seeking degrees in rangeland science/management, resulting in a severe shortage of well-trained rangeland professionals available for current and future positions. Second, in the past decade or so, lower enrollment in many of the traditional, strictly rangeland classes put rangeland science/management programs at several universities in danger of elimination or absorption by other programs, ultimately reducing the number of graduates available to fill the growing demand. In addition, many programs no longer hire faculty with primarily teaching appointments. Because of this, our programs have fewer teaching faculty with backgrounds in rangelands, and both new and current rangeland faculty are compelled to increase class sizes, course loads, and the number of program graduates. ${ }^{1}$ Given these pressures, we are faced with larger classes filled with students representing a wider audience, with sometimes drastically different backgrounds and views. Although these limited resources are challenging, they also provide an opportunity to make innovative advances in curricula and produce well-rounded students that can fill rangeland employment needs. Two primary approaches to meeting the current challenges of range programs are to teach across disciplines and across institutional boundaries.

\section{Teaching Across Disciplines}

\section{How Does This Affect Our Classes?}

Faculty are now experiencing what has been commonly referred to as an "interesting student population"- the Millennial Generation is composed to students who are considered "special" by themselves and others, "sheltered" or protected by their parents, and "confident" in their abilities. Despite many of our opinions and observations, research shows they are team-oriented and pressured to excel. ${ }^{2}$ When we go into our classrooms, many of us will find a more-diverse student population relative to the students in our previous rangeland courses. Not diverse in the more traditional "culture" way, rather diverse in majors and interests. Figure 1 shows the diversity of interests our students may have: equine, livestock production, soil science, crop science, wildlife, environmental science, wildlife habitat and management, fisheries, and rangeland ecology. These different interests bring inherent experiences with them that directly affect the flow of discussion that will occur in our classrooms.

\section{How Does This Alter Our Approach to Teaching?}

It is important for teachers to know their audience and understand their needs. In the past, teachers may have assumed all of their students came from rural range systems and had an intimate understanding of rangeland systems before entering college. Although this is still true for some students, an increasing portion of our students attracted to the field do not share this experience. In addition, not all of these students are traditional undergraduates.

There are faculty members whose reaction to diverse opinions and views in their classrooms is "change is bad!" These faculty members might look out at the students in their class and maintain a teacher-centered approach, concentrating on the content, and ignoring the students. When asked about the long-term effectiveness of their approach, many of these same faculty members may respond with "of course, my approach works," “... No, I haven't analyzed data for it," Assuming that their method of teaching to a diverse classroom is to ignore it, or worse yet, view it negatively and promote it that way in class, they are not addressing the needs of the whole class. ${ }^{3,4}$

Another way that faculty could address the diversity in their class is to embrace the diverse group of majors and take the approach that "change is good!" These faculty members could shift the balance of power in their classroom from themselves to their students. By incorporating a studentcentered teaching approach, we tend to appeal to most of the students, particularly those who are in the Millennial Generation. After all, students who later become rangeland 


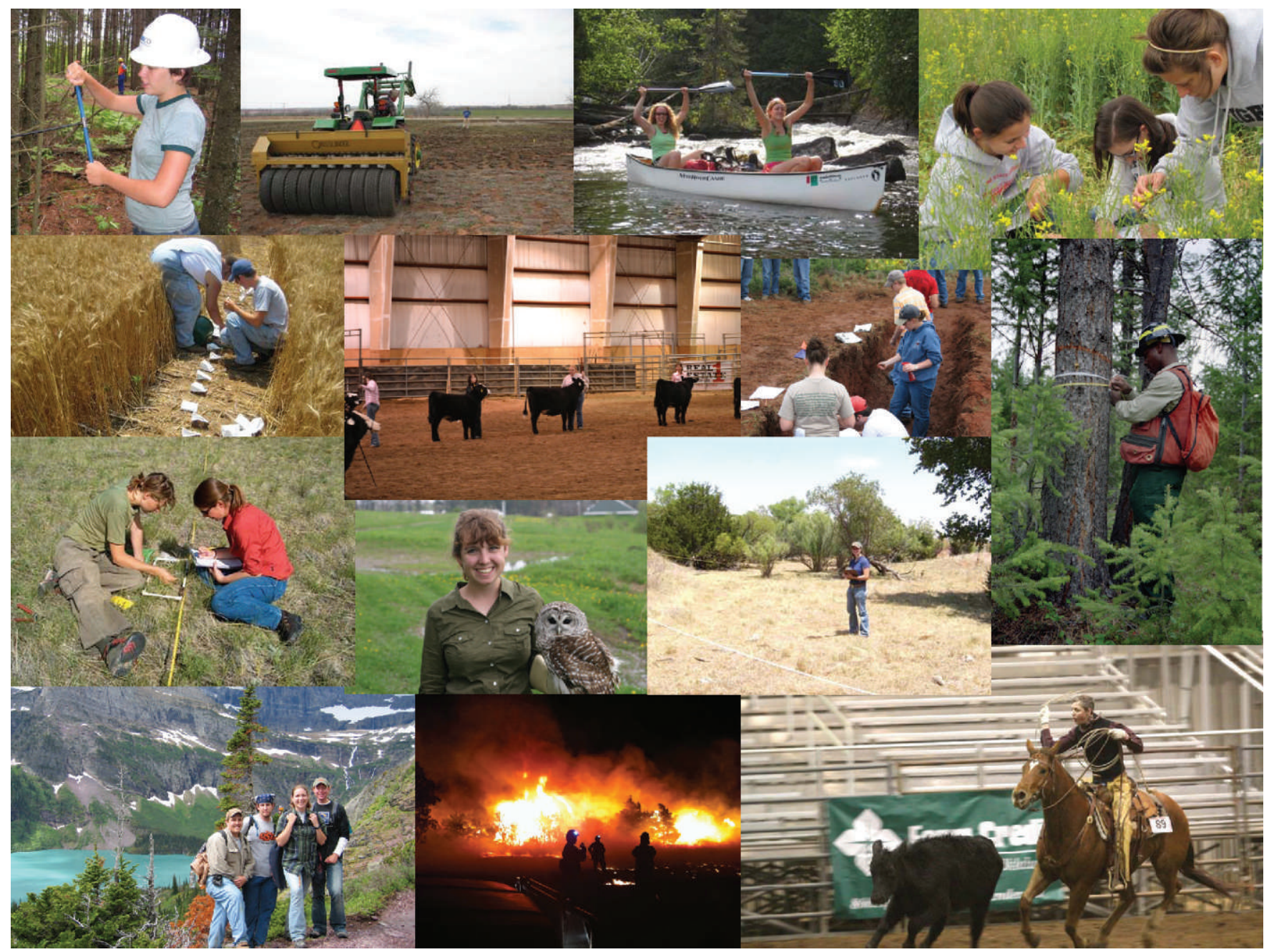

Figure 1. Photo montage of the diversity of student interests represented in current rangeland management classes: forest management, crop science, recreation, livestock production, rangeland ecology and management, wildlife rehabilitation, restoration, rodeo, environmental science, fire ecology, soil science, and forest management. Photos courtesy of: Amy Ganguli (North Dakota State University), Sara Lancaster (Oklahoma State University), Natural Resource Ecology and Management (Oklahoma State University), and Blayr Gourley (Oklahoma State University).

managers will need to communicate effectively with a diverse group of professionals and embrace public opinions. ${ }^{5}$ One useful method is to have students self-identify their major and interests at the beginning of the semester and participate in a class discussion about the range of attitudes, goals, and objectives represented by all the class members. As we discuss this diversity, we talk about the differences in everyone's viewpoints and make sure to include our own opinions in the discussion. If we expect our students to understand and appreciate differences in their classmates, we need to express our differences so that ultimately, they can understand and appreciate our differences as well.

The difficulty lies in how to imbed respect for different opinions as an important component of a course. We have found that if we incorporate this respect (i.e., as a way to build professional communication skills) as a course learning objective in our syllabus, students will embrace it as a normal expectation. For instance, we will include the following statement as one of our course objectives: "Develop an un- derstanding and appreciation for the various rangeland management techniques available to managers-and learn that there is more than one way to manage rangelands." We find it helpful to emphasize that tolerance is a learned, job-related skill and that the students are not always going to agree with their coworkers; differences in attitudes and objectives are important to acknowledge and incorporate. Thus, it is important for them to learn that respect for different opinions will help them succeed in their future career. We have found that emphasizing and refining this skill is particularly central in capstone rangeland planning courses.

Another approach we have used to incorporate the ideas from a diverse student population is to use scenario-based assessments (e.g., homework, exams) that encourage students to represent a different "culture" or opinion. Two scenarios we have posed in our exams start with requiring the student to "be someone" to whom they may or may not be similar. The first example poses the following scenario: "During a family dinner, you become involved in a conversation with your 
Environmentalist Aunt (you are her current, sole heir)...” in which the students are then asked to answer the question posed by their aunt, knowing they want to keep her happy and stay her heir. Students find this challenging for a couple of reasons. For instance, many of the production-oriented, intensive, management-based students find presenting an answer with an environmental component to be challenging (e.g., managing rangelands without herbicide use). Another challenge is adjusting to the mindset that multiple "correct" answers are possible, especially given that a student's answer could be correct and the student sitting next to them may have a different answer that is also correct. Some students have difficulty recognizing and accepting that there may be more than one right answer. The second scenario-based exam question we will provide as an example is "Upon graduation five years ago, you became a US Department of Agriculture (USDA)-Natural Resources Conservation Service Rangeland Conservationist" (working for the Environmental Protection Agency, Bureau of Land Management, US Forest Service, other agency or organization can be substituted). "Your most recent task was to..." Obviously, we have to introduce what the agency/organization is responsible for before asking the question, but it requires the students to move away from their own opinion and develop an answer that shows they have an understanding of different ways to manage a rangeland.

Although teaching courses with a widely diverse student composition can be challenging, we should encourage each other to recognize that we are helping educate even more students about rangelands.

\section{Teaching Across Institutions}

Educational opportunities can be offered across institutions to fill in identified curriculum gaps or provide novel opportunities for student learning. Education across institutions presents multiple challenges compared with a traditional classroom: juggling numerous educational goals, addressing different institutional cultures, accommodating varying educational levels and backgrounds, coordinating logistics for effective teaching, and incorporating technologies that meet teaching pedagogy. Despite these challenges, the benefits afforded by cross-institutional educational efforts to range curricula can be substantial for both teachers and students. Education across institutions is often an "emergency response" to meet student needs. We encourage teachers and range programs to see cross-institutional teaching as an opportunity available because of the ease and accessibility of technologies, which can provide educational depth and richness and practical experience for both teachers and students.

\section{What Is the Educational Goal?}

There are multiple motivations for offering educational opportunities across institutional boundaries. As rangeland programs at land-grant institutions shrink, local institutions may not have either the human infrastructure (in both available teachers and expertise in specific topics) or enrollment to offer the essential core curriculum (see SRM Accreditation Standard III on Curriculum and Advising). ${ }^{i}$ Teaching across institutions provides an opportunity for smaller rangeland programs to continue to provide quality education and training for both undergraduate and graduate students. In addition, providing a diversity of electives at the undergraduate level or graduate-only courses is a current challenge for many range programs. Cross-institution teaching provides an opportunity to provide a diversity of nonrequired courses that may be out of the expertise of local faculty, interdisciplinary courses collaboratively taught by a collection of individuals who are disciplinary experts, or courses on cutting-edge topics. ${ }^{6}$ One strength of cross-institutional teaching is the ability to identify educational goals that cannot be met within a traditional teaching scenario, which can be addressed by putting classrooms on the global stage in cross-institutional teaching.

\section{What Institutions?}

Cross-institution teaching need not be limited to 4-year academic institutions with established rangeland programs. However, the type of institutions involved in a course will influence the content, pace, format, and approach of a course. ${ }^{7}$ Teaching across programs from two land-grant institutions involves students and teacher(s) with similar institutional cultures and expectations. However, teaching across types of institutions (2-year, 4-year liberal areas, 4-year land-grant, international institutions, and agencies) brings divergent expectations in student performance, educational purpose, and grading needs. For example, many international institutions have one final exam and no other form of student assessment (or graduate students may not be required to take course work at all). Rangeland management agencies may only be concerned with specific deliverables, such as mastery of specific skills (e.g., implementation of ecological site descriptions for rangeland management), or improvement in job performance to assess learning. One approach is to provide course materials across institutions but to leave overall delivery, assessment criteria, and grading to the local institution. ${ }^{6}$

\section{Who Are the Students?}

Students come to a course with their own strengths and constraints: previous life experience, expectations of the material, educational development, educational stage, life obligations, and professional commitments. The same subject material requires different delivery for undergraduates, nontraditional undergraduates, graduate students, working professionals, or some mix of these broad student types. One approach to responding to a diversity of student types is to offer courses in a modular format, where course materials can be offered

\footnotetext{
' For information on the core curriculum, see SRM Standard III on Curriculum and Advising in the Society for Range Management University Accreditation Program Handbook available at: http://rangelands.org/accreditation/ SRM\%20Accreditation\%20Handbook\%20approved\%20revised_ April\%202011\%20_2_.pdf.
} 
at multiple levels simultaneously. In addition, nontraditional students and rangeland professionals seeking continuing education opportunities generally need more flexible timing than traditional undergraduate students.

\section{How Are You Going to Teach?}

The "distance education" model is well-established and powerful. Cross-institutional teaching, however, is not synonymous with distance or online learning. Cross-institutional teaching can follow multiple models including synchronous lectures with remote access, asynchronous learning (recorded lectures, use of books and other course materials, such as exercises, combined with online discussions), intensive workshops, and field-based courses. When designing a cross-institutional rangeland course, it is important to critically evaluate 1) the educational objectives, 2) the teaching models in the context of these educational objectives, and 3) the delivery methods best suit to your students, teaching objectives, and logistical constraints. Traditional undergraduate students may be more comfortable with live lecture information, whereas nontraditional undergraduate students or professionals may be satisfied with recorded lectures that give them more flexibility or a short, discrete time to dedicate to the course (e.g., an intensive workshop or "field camp" model). Teaching across institutions provides an opportunity to "break the mold" of traditional teaching formats. Students from multiple institutions can compare and contrast their local rangelands via online video exchange and follow these discussions up with a virtual or in-person field trip. For our student population, these experiences are beneficial to their overall education because they will broaden their experiences and understanding of the breadth of rangeland ecosystems.

\section{What Technologies Are Effective?}

Regularly offered teaching across institutions is made possible through recent technological advances. The traditional distance-learning model requires specific classroom technology, both at the focal institution and the remote locations. These technologies are effective but also a bit awkward. If teachers and students have high-speed Internet access, lowcost options exist to facilitate synchronous teaching across vast geographic areas. Although this technology is powerful, teachers should critically 1) consider which technologies meet a priori teaching goals, 2) test those technologies for reliability, 3) monitor which technologies are actually used by students, and 4) assess how effective technologies are meeting learning objectives. Skype (Skype, Inc, Palo Alto, CA), ${ }^{\text {,i }}$ Google Groups (Google, Inc, Mountain View, CA), ${ }^{\text {iii }}$ iLink (iLink Systems, Bellevue, WA), ${ }^{\text {iv }}$ and Adobe Connect (Adobe Systems Inc, San Jose, CA) ${ }^{v}$ all provide

\footnotetext{
i'Skype, http://www.skype.com.

iii Google Groups, http://groups.google.com.

iv iLink, http://ilink-systems.com.

${ }^{v}$ Adobe Connect, http://www.adobe.com/products/adobeconnect.html.
}

venues for cross-institutional meetings and synchronous courses. These platforms require only an echo-cancelling microphone, a fast Internet connection, and a back-up plan when technology fails on a given day. In addition, lectures and discussions can easily be recorded and especially benefit students who speak English as a second language. ${ }^{6}$ In a recent distributed landscape genetics course, the teachers found online discussion groups and live "office hours" were not used by the students unless required for a participation grade. ${ }^{6}$ The teachers used this information to modify the course on the second offering with discussion across institutions during class time and incentives for using student discussion boards.

\section{Bringing It All Together-Case Study}

Perhaps the most promising platform for cross-institutional teaching is blended learning, an approach that synthesizes face-to-face learning with distributed (e.g., online) elements. ${ }^{8}$ A landscape genetics, distributed, graduate course (DGC), led by Helene Wagner (University of Toronto) and Lisette Waits (University of Idaho) and offered across multiple institutions worldwide, is an example of this approach. ${ }^{6}$ The course was developed to provide educational and training needs for graduate students in an emerging, interdisciplinary field, where expertise in all areas was unlikely to reside at a single institution. Experts in the field, with varied backgrounds, combined resources to offer a course across disciplines. The course combined local seminars (local explanations/discussion), asynchronous activities (lectures 2010, a discussion board), synchronous cross-institutional learning (live lectures and cross-section discussion 2012, presentation of group projects), experiential learning (hands-on laboratory exercises, cross-institutional group projects, and production of a manuscript for publication), and a workshop component (final face-to-face synthesis meeting after course completion). ${ }^{6}$ The instructors found that live interaction was best when possible (live lectures vs. watching recorded lectures) and coming together for a final synthesis meeting enhanced the educational experience. One "valueadded" benefit was students became comfortable with online meeting technologies, opening the opportunity to collaborate with scientists around the world on future projects. The DGC allowed instructors to combine local teaching and support with expertise from around the world, bringing together the best of local and global teaching resources.

\section{Conclusions}

Current changes in rangeland programs provide a suite of teaching challenges. Although these challenges are daunting, we encourage teachers and administrators to embrace the changes and take advantage of the opportunity to develop new, exciting, and effective learning approaches. Although the student "type" in rangeland programs is changing, it may be a better representation of the breadth of viewpoints students are likely to encounter "on the job." The student diversity may actually create a stronger environment for preparing our students 
for the reality of rangeland management in today's world. Teaching to a broader cross-discipline audience and across institutions may be challenging. However, we believe, in the end, it is a benefit to both students and to programs, particularly those that struggle to persist. We are no longer limited by local resources; globalization of courses provides a wide-range of opportunities for rangeland education. However, embracing changes and alternative teaching platforms requires flexibility and adaptability from both teachers and students. Finally, one major concern with teaching across disciplines and institutions is providing the institutional flexibility to support these courses that may not follow the rules of the institutional norms. Sustaining innovative and effective cross-cutting teaching models requires time and dedication; sustaining these models over time requires institutional support for all faculty members involved, so these courses can be offered long-term and not just as a short-term, novelty experience.

\section{Acknowledgments}

The Landscape Genetics Distributed Graduate Course (LGDGC, 2010 and 2012), was led by Helene Wagner and Lisette Waits in 2010 and Wagner, Waits, and Murphy in 2012. The course was originally a Distributed Graduate Seminar ("Landscape Genetics: Developing Best Practices for Testing Landscape Effects on Gene Flow") through the National Center for Ecological Analysis and Synthesis, a center funded by the National Science Foundation (EF-0553768, Wagner and Waits). We appreciate the assistance Blayr Gourley provided with the figure format.

\section{Literature Cited}

1. Thurow, T. L., M. M. Kothman, J. A. Tanaka, and J. P. Dовrowolski, 2007. Which direction is forward: perspectives on rangeland science curricula. Rangelands 29(6):40-51.
2. Howe, N., and W. Strauss. 2003. Millennials and K-12 schools. Great Falls, VA, USA: LifeCourse Associates. 181 p.

3. BAin, K. 2004. What the best college teachers do. Cambridge, MA, USA: Harvard University Press. 207 p.

4. Lindblom-Ylanne, S., K. Trighell, A. Nevgi, and P. Ashwin, 2006. How approaches to teaching are affected by discipline and teaching context. Studies in Higher Education 31:285-298.

5. Kreuter, U. 2001. Preparing for the future of range science. Rangelands 23(5):24-26.

6. Wagner, H., M. A. Murphy, R. Holderegger, and L. Waits. 2012. Developing an interdisciplinary, distributed graduate course for twenty-first century scientists. BioScience 62:182-188.

7. Owley, J., and A. R. Rissman. 2011. Distributed graduate seminars: an interdisciplinary approach to studying land conservation. Pace Environmental Law Review Online Companion 2:88-101.

8. Garrison, D. R., and N. D. Vaughan. 2008. Blended learning in higher education: framework, principles, and guidelines. Hoboken, NJ, USA: Jossey-Bass. 245 p.

Authors are Professor, Dept of Natural Resource Ecology and Management, Oklahoma State University, Stillwater, OK 74078, USA, Karen.hickman@okstate.edu (Hickman); and Assistant Professor, Dept of Ecosystem Science and Management, University of Wyoming, Laramie, WY 82071, USA (Murphy). Melanie Murphy was supported in part by the Wyoming NASA Space Grant Consortium, NASA Grant NNX10A095H. Karen R. Hickman was supported in part by the USDA Higher Education Challenge Grant (CRIS 0222937; "Repositioning Rangeland Education for the 21st Century"). 